\title{
Consideraciones éticas sobre la gestión de la salud en la crisis sanitaria generada por el SARS-CoV-2
}

Ethical considerations on the management of health during the health crisis caused by SARS-CoV-2

Considerações éticas sobre a gestão da saúde na crise sanitária gerada pelo SARSCoV-2

\section{Gilberto Antonio Bastidas-Pacheco, MD., MSc., PhD. ${ }^{1}$ (I)}

1. Médico Cirujano, Magister en Salud Pública y Gestión de Hospitales, Doctorado en Parasitología. Departamento de Salud Pública e Instituto de investigaciones Médicas y Biotecnológicas, Facultad de Ciencias de la Salud, Universidad de Carabobo. Carabobo, Venezuela.

Correspondencia. Gilberto Antonio Bastidas Pacheco. Universidad de Carabobo, Campus Barbula, Naguanagua, Carabobo, Venezuela. Email. bastidasprotozoo@hotmail.com

\section{INFORMACIÓN DEL ARTÍCULO:}

Artículo recibido: 6 de abril de 2021

Artículo aceptado: 17 de noviembre de 2021

DOI: https://doi.org/10.29375/01237047.4120

Cómo citar: Bastidas-Pacheco GA. Consideraciones éticas sobre la gestión de la salud en la crisis sanitaria generada por el SARS-CoV-2. MedUNAB [Internet]. 2021;24(3):384-386. doi: https://doi.org/10.29375/01237047.4120

Palabras claves:

SARS-CoV-2; COVID-19; Ética; Administración Sanitaria; Investigación

Keywords:

SARS-CoV-2; COVID-19; Ethics; Health Services Administration; Research.

Palavras-chave:

SARS-CoV-2; COVID-19; Ética; Administração Sanitária; Pesquisa. 


\section{Sr. editor:}

En el área de la salud, las implicaciones éticas que tienen la investigación y la administración de recursos en la crisis sanitaria causada por el SARS-CoV-2 resultan particularmente importantes. La investigación se realiza con el fin de descifrar el comportamiento biológico del virus que causa la enfermedad y la forma de combatir la infección, entre otros aspectos de interés que parten de la imperiosa necesidad de generar una base sólida de evidencias. La administración de los recursos, por su parte, está apoyada en el conocimiento generado con la investigación, y está enfocada en mejorar la atención, la intervención y la gestión sanitaria. La información confiable facilita la toma de decisiones sobre la prevención de la infección, sanación y rehabilitación de quienes padecen complicaciones derivadas de la enfermedad $(1,2)$.

El debate sobre qué ensayos clínicos deben interrumpirse o continuarse es álgido. Muchos apuestan por terminar algunos considerados inútiles, otros cuyo beneficio es a largo plazo o indirecto. Esto teniendo en cuenta la alta inversión económica que requieren, pero también porque en pandemia se gana más en control de la transmisión si los sujetos de prueba no abandonan el aislamiento para acudir a los ensayos, pues con esta acción se reduce el riesgo de contacto con SARS-CoV-2 (3). Otros afirman que deben continuarse los ensayos clínicos de moderado a alto impacto, como por ejemplo los modificadores de la enfermedad (de impacto moderado) o los medicamentos con elevado potencial para salvar vidas (alto impacto). Esto, sin embargo, genera alta carga económica e implica mayor riesgo de contagios en los individuos sometidos a prueba (1).

La investigación en época de pandemia del SARS$\mathrm{CoV}-2$ debe realizarse vigilando los principios éticos fundamentales de respeto por la persona, beneficencia y justicia, particularmente cuando los mismos, como producto del proceso investigativo, entran en conflicto. Entonces es importante la priorización de la seguridad de los participantes en los ensayos clínicos, por encima de la validez de los datos, así como la inferencia causal propia de los ensayos aleatorios controlados, los preferidos en estudios clínicos, aunque los más controvertidos éticamente, a pesar de que se brinden a los grupos controles los mejores cuidados de apoyo, situación que se complica aún más para COVID-19, en relación con las medidas paliativas que se deben administrar a los grupos control, porque son muchos los aspectos que se desconocen sobre esta enfermedad. Un clásico ejemplo de afectación de principios éticos se evidencia en los ensayos de exposición en humanos, aquellos donde deliberadamente se infecta con el agente causal a voluntarios para acelerar, entre otros aspectos, el desarrollo de vacunas; o los estudios donde los sujetos reciben la vacuna experimental o un placebo para determinar la eficacia y eventual aprobación de la misma para su aplicación masiva $(4,5)$.

En pandemia es común que los profesionales de Ciencias de la Salud experimenten "angustia moral" porque piensan en lo que es correcto para ellos, pero no pueden actuar conforme a esto. Fundamentalmente, debido a las claras diferencias socioeconómicas de la población (el COVID-19 al igual que otras enfermedades infecciosas no es socialmente neutral, ya que afecta a pobres y ricos en forma desigual) y en la infraestructura sanitaria (en pandemia siempre sobrepasada su capacidad) en lo que a estándares de cuidados se refiere, esto a pesar de los esfuerzos que los gobiernos realizan para igualar las oportunidades en el trato sanitario (al menos en la igual distribución de pruebas y de tratamientos); es decir, en la equidad en salud, pues es en las poblaciones pobres donde se registra la mayor carga financiera aunque estén cubiertos por la sanidad social $(5,6)$.

En lo que respecta a la Administración de Salud en pandemia (la deseada, aquella que se adapta a los contextos locales), éticamente no debe ser un subproducto del privilegio político o educativo y menos algo dependiente de la raza o etnia dominante de cada país, de la segregación residencial en las comunidades urbanas o rurales, ni de aspectos tan simples como la capacidad para quedarse en casa sin que esto signifique el deterioro de la estabilidad económica, tampoco del hacinamiento en comunidades con escasos espacios al aire libre o en el hogar (casas de múltiple ocupación o pequeñas sin espacio exterior), del tipo de empleo (específicamente los que atienden al público como los transportadores y el personal sanitario y de servicios; de la tecnología de información y comunicación; o de la seguridad alimentaria (6-8).

Tampoco resulta un comportamiento ético por parte de los integrantes de los grupos sociales que, por miedo a adquirir la infección, sometan a los profesionales de la Salud por ser considerados altamente transmisores del SARS-CoV-2, al acoso, estigmatización o violencia física en su quehacer en procura de asegurar la atención sanitaria, como se ha observado en algunas regiones del mundo, en que se ha llegado incluso al ostracismo de los sanitaristas, o de los sobrevivientes de la enfermedad, debido a que un grupo de personas con compresión inadecuada de la información, violan los principios éticos fundamentales como la autonomía, responsabilidad, beneficencia, el bien común y la justicia (9). 
En conclusión, es prioritario un acercamiento ético a la pandemia del COVID-19. Debe prevalecer la responsabilidad compartida o sinérgica entre quienes investigan y administran la salud y entre aquellos que son objeto de ambas intervenciones con base en la búsqueda de soluciones colectivas, sustentadas en la educación sanitaria adecuada, producto de la investigación clínica hecha con apego a los valores éticos de respeto, beneficencia y justicia, y con estrategias culturalmente apropiadas a cada comunidad en consideración de los diferentes matices que definen a una población, con el objetivo de reducir las disparidades en salud y promover la equidad.

\section{Conflictos de intereses}

El autor declara no tener conflictos de intereses.

\section{Referencias}

1. Meagher KM, Cummins NW, Bharucha AE, Badley AD, Chlan LL, Wright RS. COVID-19 Ethics and Research. Mayo Clin Proc [Internet]. 2020;95(6):1119-1123. doi: https://doi.org/10.1016/j. mayocp.2020.04.019

2. Acosta-Ortiz AM. La toma de decisiones de gobiernos y sectores de la sociedad, intuiciones y datos en tiempos de pandemia SARS-COVID-19. MedUNAB [Internet]. 2020;23(3):369-371. doi: https://doi.org/10.29375/01237047.4009
3. Mueller P, Montori V, Bassler D, Koenig B, Guyatt G. Ethical Issues in Stopping Randomized Trials Early Because of Apparent Benefit. Ann Intern Med [Internet]. 2007;146(12):878-881. doi: https://doi. org/10.7326/0003-4819-146-12-200706190-00009

4. Bastidas-Pacheco G. Ética en enfermedades emergentes que causan pandemia. Caso covid-19. Revista Médica de la Universidad de Costa Rica [Internet]. 2020;14(1):89-91. Recuperado a partir de: https://revistas.ucr.ac.cr/index.php/medica/article/ view/42283/42523

5. Wang Z, Tang K. Combating COVID-19: health equity matters. Nat Med [Internet]. 2020;26:458. doi: https://doi.org/10.1038/s41591-020-0823-6

6. Bambra C, Riordan R, Ford J, Matthews F. The COVID-19 pandemic and health inequalities. $\mathrm{J}$ Epidemiol Community Health [Internet]. 2020;74:964-968. doi: https://doi.org/10.1136/jech2020-214401

7. Van Dorn A, Cooney RE, Sabin ML. COVID-19 exacerbating inequalities in the US. Lancet [Internet]. 2020;395(10232):1243-1244. doi: https:// doi.org/10.1016/S0140-6736(20)30893-X

8. Webb-Hooper M, Nápoles AM, Pérez-Stable EJ. COVID-19 and Racial/Ethnic Disparities. JAMA [Internet]. 2020;323(24):2466-2467. doi: https://doi. org/10.1001/jama.2020.8598

9. Bagcchi S. Stigma during the COVID-19 pandemic. Lancet Infect Dis [Internet]. 2020;20(7):782. doi: https://doi.org/10.1016/S1473-3099(20)30498-9 